\title{
Matematik Öğretmeni Adaylarının Matematik Okuryazarlık Öz- Yeterliklerinin Çeşitli Değişkenler Açısından İncelenmesi
}

\section{Bünyamin Aydın ${ }^{1} \quad$ Şefika Çulha $^{2} \quad$ Gizem Yeşilgöz Şengün ${ }^{3}$}

\section{Type/Tür:}

Research/Araştırma

Received/Geliş Tarihi:

December 6/6 Aralık 2019

Accepted/Kabul Tarihi:

January 20/ 20 Ocak 2020

Page numbers/Sayfa No: 860-874

Corresponding

Author/İletişimden

Sorumlu Yazar:

bunyaminaydin63@hotmail. com

\section{$\checkmark$ iThenticate}

This paper was checked for plagiarism using iThenticate during the preview process and before publication. / $\mathrm{Bu}$ çalışma ön inceleme sürecinde ve yayımlanmadan önce iThenticate yazılımı ile taranmıştır.

Copyright (c) 2017 by Cumhuriyet University, Faculty of Education. All rights reserved.

\section{Öz}

Matematik eğitimi ve öğretiminin nitelikli olabilmesi için eğitimin temel taşı olan öğretmenlerin matematik okuryazarlık öz-yeterlik (MOÖ)'lerinin yüksek olması ve sürekli geliştirilmesi gerekmektedir. Matematik öğretmen adaylarının MOÖ'lerinin yüksek olması için düşünme, sorgulama ve üretme yeteneklerin geliştirilmesi ilk sırada yer almalıdır. Bu nedenle, çalışmada ilköğretim matematik öğretmeni adaylarının MOÖ düzeylerinin belirlenmesi amaçlanmaktadır. Bu doğrultuda, bu çalışmanın amacını ilköğretim matematik öğretmeni adaylarının MOÖ düzeylerine yönelik sorulara verdikleri yanıtların aile eğitim durumlarına ve cinsiyetlerine göre farklılık gösterip göstermediğinin belirlenmesi oluşturmaktadır. Bu araştırma,2019-2020 eğitim-öğretim yılı güz döneminde Alanya Alaaddin Keykubat Üniversitesi Eğitim Fakültesi İlköğretim Matematik Öğretmenliği bölümünde öğrenim görmekte olan toplam 73 son sinıf öğrencisi öğretmen adayı ile yüz yüze anket tekniği kullanılarak yapılmıştır. Araştırmadan elde edilen veriler; ortalama, t-testi ve tek yönlü varyans analizi yardımıyla analiz edilmiştir. Araştırmada öğretmen adaylarının önemli bir bölümünün MOÖ’lerinin gelişmiş olduğu sonucuna ulaşılmıştır. Diğer taraftan, annebaba eğitim durumu ile okuryazarlık öz-yeterlik puanları arasında anlamlı bir ilişkiye rastlanmamıştır. Anne-baba eğitim durumunun MOÖ düzeyine herhangi bir katkısının olmadığı saptanmıştır. Öğretmen adaylarının MOÖ puanları ile cinsiyetleri arasında anlamlı bir farklılık olduğu tespit edilmiştir. Erkek öğretmen adaylarının MOÖ puan ortalamasının, kadın öğretmen adaylarının MOÖ puan ortalamasından daha düşük olduğu sonucuna ulaşılmıştır. Okullarda matematik ders programı okuryazarlı̆̆ı, mantıksal akıl yürütme, matematik öğretiminde kavram yanılgıları gibi derslere ağırlık verilmesi öğretmen adaylarının MOÖ’lerinin artmasına; düşünme, sorgulama ve üretme yeteneklerin gelişmesine katk1 sağlayacaktır.

Anahtar Kelimeler: Matematik eğitimi, öz-yeterlik, matematik okuryazarlığı, ilköğretim, öğretmen adayları.

\section{Suggested APA Citation/Önerilen APA Atıf Biçimi:}

Aydın, B., Çulha, Ş., \& Yeşilgöz Şengün G. (2020). Matematik öğretmeni adaylarının matematik okuryazarlık öz-yeterliklerinin çeşitli değişkenler açısından incelenmesi. Cumhuriyet International Journal of Education, 9(3), 860-874. http://dx.doi.org/10.30703/cije.656316

\footnotetext{
1 Prof. Dr., Necmettin Erbakan Üniversitesi, Ahmet Keleşoğlu Eğitim Fakültesi, Konya/Türkiye Prof.Dr., Necmettin Erbakan University, Ahmet Keleşoğlu Faculty of Education, Konya/Türkiye e-mail: bunyaminaydin63@hotmail.com ORCID ID: orcid.org/0000-0002-0133-9386

2 Yüksek Lisans Öğrencisi, Alanya Alaaddin Keykubat Üniversitesi, Antalya/Türkiye Master Student, Alanya Alaaddin Keykubat University, Antalya/Türkiye e-mail: sfkmtl@hotmail.com ORCID ID: orcid.org/0000-0002-0007-9033 3Öğretmen, Milli Eğitim Bakanlığı, Antalya/Türkiye Teacher, Ministry of National Education, Antalya/Türkiye e-mail: gizemyesilgoz@hotmail.com ORCID ID: orcid.org/0000-0002-2869-6287
} 


\title{
Examining Mathematics Literacy Self-Efficacy for Mathematics Teacher Candidates in Terms of Various Variables
}

\begin{abstract}
In order to be qualified in mathematics education and training, mathematics literacy self-efficacy (MLSE) of teachers, which is the cornerstone of education, should be high and continuously developed. Developing thinking, questioning and producing skills should be the first priority for mathematics teacher candidates to have high MLSE. Therefore, it is aimed to determine the levels of MLSE of primary school mathematics teacher candidates. In this respect, the aim of this study is to determine whether primary mathematics teacher candidates' answers to the questions related to their levels of MLSE differ according to their parents' educational status and gender. This research was carried out by using face - to - face questionnaire technique with 73 senior students- teacher candidates who are studying in Alanya Alaaddin Keykubat University Faculty of Education Elementary Mathematics Teaching Department in fall semester of 2019-2020 academic year. The data obtained from the study were analyzed by using mean, t-test and one-way analysis of variance. In the study, it has been concluded that a significant number of teacher candidates have developed MLSE. In the study, no significant relationship was found between the educational status of parents and literacy self-efficacy scores. It was found that the educational status of the parents did not contribute to the level of MLSE. There was a significant difference between the scores of teacher candidates' MLSE scores and gender. It was concluded that the mean score of MLSE of male students was lower than the mean score of MLSE of female students. Focusing on courses such as literacy of mathematics curriculum in schools, logical reasoning, misconceptions in mathematics teaching will contribute to the increase of teacher candidates' MLSE, development of thinking, questioning and producing abilities.
\end{abstract}

Keywords: Mathematics education, self-efficacy, mathematics literacy, primary education, teacher candidates.

\section{Giriş}

Matematik, günlük hayatımızda karşılaştığımız her türlü problemi anlama ve çözüme kavuşturma süreçlerinin bütünüdür (Koyuncu ve Haser, 2012). Bu süreçte toplumdaki kişilerin, yalnız okuma-yazma ve dört işlem bilmesiyle yetinilmemeli, herkesin matematikte okuryazar olması amaçlanmalıdır (Ersoy, 1997). Literatürdeki okuryazarlık ile ilgili tanımlar incelendiğinde matematik dersine olan ilgi, tutum, motivasyon, algı, kaygı ve çalışma disiplini (Aksu ve Güzeller, 2016) dişında okuryazarlık ile ilişkili bulunan bir diğer kavramın ise özyeterlik olduğu görülmektedir. Hâlbuki matematiksel okuryazarlığın ağırlıklı alan olarak belirlendiği Uluslararası Öğrenci Değerlendirme Programı (PISA) 2012 uygulamasında Türkiye'nin, 34 Ekonomik İşbirliği ve Kalkınma Örgütü (OECD) ülkesi arasında 31. sırada yer aldığı görülmektedir. Türk öğrencilerin PISA sinavlarında son siralarda yer alması matematik öz-yeterlik algılarının yeterli olmadığını göstermektedir. $\mathrm{Bu}$ sonuçlara göre eleştirel ve analitik düşünme, sonuç çıkarma ve bu sonuçları günlük hayatına aktarma konusunda öğrenciler yetersiz kalmaktadırlar. Yetersizliğin sebebi araştırılırken, öğretmenlerin öz-yeterlik düzeylerinin düşük olmasının etkisi var mı sorusu akıllara gelmektedir. Söz konusu öğrencilerin öz-yeterlik algılarının güçlenmesi, ancak öğretmenlerin, öğrencilerinin ihtiyaçlarına ve niteliklerine uygun biçimde öğretim etkinlikleri yapmalarına bağlıdır (Senemoğlu, 2001). 
Goodson ve Hargreaves (2005; akt. Demirtaş, Cömert ve Özer, 2011) toplumda bireyleri istenilen şekilde yetiştirme sorumluluğunun öğretmenlerde olması nedeniyle, öğretmenlik mesleğinin önemli mesleklerden biri olduğunu ifade etmişlerdir. Yetişen bireylerin yaşam boyu öğrenme becerilerine sahip, bilgilerini yenileyen, değişime açık olan, gelişmeleri takip eden, bilgiyi bilinçli tüketen ve üreten, bilgi becerilerine sahip, teknolojiyi kullanabilen ve kendi kendine öğrenebilen (Akkoyunlu ve Kurbanoğlu, 2003), bilgiye ulaşan, bilgiyi düzenleyen, değerlendiren, sunan ve iletişim kurabilen (Akkoyunlu, 1995; Aydın, 2003) bireyler olmaları beklenmektedir. Öğretmenlerin yeniliklere uyum sağlamaları yetiştirdikleri öğrencileri de etkilemektedir. Ayrıca öğretmenlerin başarılı olmaları, onlara sunulan imkanlar, öğrencilerin ve ailelerinin ilgileri ve çalışma ortamı gibi dışsal faktörlerden etkilenirken, öz-yeterlik algısı ve mesleğe yönelik tutumları gibi içsel faktörlerden de etkilenmektedir (Demirtaş vd., 2011). Eğitimin temel taşı olan öğretmenlerin okuryazarlık öz-yeterlik algılarının yüksek olması beklenmektedir. Böylelikle, öğretmen veya öğretmen adaylarının matematik okuryazarlık seviyelerinin saptanması ve önemli düzenlemelerin yapılması gerekmektedir (Güneş ve Gökçek, 2013). Bu düzenlemeler, müfredatlar güncellenerek yapılabileceği gibi öğretmen adaylarının kendilerini geliştirmelerine imkân tanınarak da yapılabilecektir.

Öz-yeterliği ölçmeye yönelik alan yazında birçok çalışma bulunmaktadır. Akkoyunlu ve Kurbanoğlu (2003) çalışmalarında öğretmen adaylarının bilgisayar özyeterlik algıları ve bilgi okuryazarlıkları arasındaki ilişkiyi ve yıllar içinde değişimi incelerken (2004) bir diğer çalışmalarında ise farklı kademelerde ve farklı branşlardaki öğretmenlerin bilgi okuryazarlığı öz-yeterlik inançlarını araştırmışlardır. Özgen ve Bindak (2008), yaptıkları bir çalışmada öğretmen adaylarının matematik okuryazarlığına ilişkin öz-yeterlik algılarının tespiti için geçerli ve güvenilir bir ölçek geliştirmişlerdir. Demirtaş vd. (2011), öğretmen adaylarının öz-yeterlik inançlarını ve mesleğe olan tutumlarını incelemişlerdir. Koyuncu ve Haser (2012), sınıf öğretmeni adaylarının MOÖ’lerini çeşitli demografik değişkenlere göre karşılaştırmışlardır. Altıntaş vd. (2012), çeşitli bölümlerde eğitim görmekte olan öğretmen adaylarının MOÖ algılarının çeşitli değişkenler bakımından farklılık gösterip göstermediğini incelemişlerdir. İlhan (2015), ilköğretim matematik öğretmen adaylarına yönelik görsel matematik okuryazarlığı ölçeği geliştirmiş ve görsel matematik okuryazarlığı ile geometri başarıları arasındaki ilişkiyi incelenmiştir. Tarım vd. (2015), Adana'da ilköğretim okullarında görev yapan öğretmenlerin MOÖ düzeylerini belirlemiş ve çeşitli değişkenler açısından karşlaştırmışlardır. Zehir ve Zehir (2016) ve Dinçer vd. (2016) ise ilköğretim matematik öğretmen adaylarının MOÖ düzeylerini çeşitli değişkenler açısından incelemişlerdir.

Okul öncesi dönemden itibaren hayatımızın her alanında matematiğin yer alması ve birçok bilgi ve becerinin ilköğretimde, ilköğretim öğretmenleri tarafından kazandırılıyor olması nedeniyle ilköğretim öğretmenlerinin MOÖ'nün yüksek olması beklenmektedir. Kaliteli ve başarılı bir matematik öğretimi için öğretmen adaylarının MOÖ'nün geliştirilmesi (Koyuncu ve Haser, 2012) ve mesleki gelişimleri açısından hizmet öncesinde birtakım önlemlerin alınması (Yenilmez ve Turğut, 2012) gerekmektedir. Bu önlemler alınırken matematik öğretmen adaylarının MOÖ'lerinin yüksek olması için düşünme, sorgulama ve üretme yeteneklerin geliştirilmesi ilk 
sırada yer almalıdır. Bu nedenle, çalışmada ilköğretim matematik öğretmeni adaylarının MOÖ düzeylerinin belirlenmesi amaçlanmaktadır. Bu doğrultuda, bu çalışmanın amacını ilköğretim matematik öğretmeni adaylarının MOÖ düzeylerine yönelik sorulara verdikleri yanıtların aile eğitim durumlarına ve cinsiyetlerine göre farklılık gösterip göstermediğinin belirlenmesi oluşturmaktadır. Bu çalışma sonunda elde edilecek bulgular, eğitim kurumlarının öğretmen adaylarının yetiştirilmesinde MOÖ konusunda öğretim müfredatlarının geliştirilmesine katkı sağlayacaktır.

\section{Matematikte Okuryazarlık}

1739 sayılı Millî Eğitim Temel Kanunu'nda belirlenmiş olan Genel Amaçlar ve Temel İlkeler doğrultusunda Matematik Dersi Öğretim Programı'nda, öğrencilerin matematiksel okuryazarlık becerilerinin gelişimi ve bunu aktif olarak kullanabilmeleri amaçlanmaktadır (MEB, 2018). PISA'nın temel özellikleri arasında yer alan okuryazarlık kavramı, öğrencilerin karşılaştıkları herhangi bir durumdaki problemi tanımlama, yorumlama, çözme, bilgi ve becerileri kullanma, çözümleme, akıl yürütme ve etkili iletişim kurma yeterlikleri olarak tanımlanmaktadır (PISA, 2012). PISA'da tanımlandığı şekliyle matematik okuryazarlığı, öğrencilerin matematiği kullanabilmeleri, aldıkları eğitimin zenginliği ve yeterliği ile ilişkilendirilmektedir (OECD, 2013c, s.28-30). PISA 2015 Ulusal Raporunda belirtildiği üzere matematik okuryazarlığı, öğrencilerin matematiği çözme, günlük hayata aktarabilme ve yorumlama kapasitesini ölçmeye odaklanmaktadır (PISA, 2015). Hope (2007; akt. Koyuncu ve Haser, 2012)'a göre matematik okuryazarlığı, kişinin gerçek yaşamda gerekli olan matematik bilgisini kullanma ve buna bağlı olarak mantığa uygun kararlar alabilmesidir.

Matematik okuryazarlığ1 ile ilgili (Aksu ve Güzeller, 2016; Başaran, 2005; Ersoy, 1997; Güneş ve Gökçek, 2013; İlhan, 2015; Önal ve Çetin, 2014) ve okuryazarlık öz-yeterliği ile ilgili (Akkoyunlu ve Kurbanoğlu, 2003, 2004; Altıntaş vd., 2012; Dinçer vd., 2016; Güneş vd., 2013; Koyuncu ve Haser, 2012; Özgen ve Bindak, 2008; Tarım vd., 2015; Yenilmez ve Turğut, 2012; Zehir ve Zehir, 2016) çok sayıda çalışma bulunmaktadır. Matematik okuryazarlığında, öz-yeterlik kavramının en yordayıcı değişken olduğu tespit edilmiştir (Aksu ve Güzeller, 2016; Duran ve Bekdemir, 2013; Güneş vd., 2013; Güneş ve Gökçek, 2013). Schulz'e (2005; akt. Altıntaş vd., 2012) göre matematik okuryazarlığı yüksek olan bireylerin öz-yeterlik algılarının da yüksek olduğu ifade edilmiştir. Alanyazında yapılmış çok sayıda çalışma olmasına rağmen bu çalışmanın örneklemine dâhil edilen öğretmen adaylarının sosyo-kültürel yapıları ve üniversite giriş puanları farklı olduğundan diğer çalışmalardan farklılık arz etmektedir.

\section{Öz-yeterlik}

Senemoğlu'nun aktarımına göre Bandura (1986), öz-yeterlik kavramını 'Bireyin, belli bir performansı göstermek için gerekli etkinlikleri organize edip başarılı olarak yapma kapasitesine ilişkin kendi yargısıdır.(Bandura, 1986, s.391)' şeklinde açıklamıştır. Aşkar ve Umay'a (2001) göre öz-yeterlik algısı üst seviyede olan kişiler, 1srarlı, sabırlı, çaba gösteren ve olumsuzluklar karşısında geri dönmeyen kişilerdir. Öz-yeterlik kavramı, öğretmenlik mesleğine ilişkin önemli bir değişken (Akgün, 2013) ve bir öğretmende olması gereken bilgi, beceri ve tutumlar (Demirtaş vd., 2011) olarak kabul edilmektedir. $\mathrm{Bu}$ nedenlerle, öğretmenlerin ve öğretmen adaylarının öz- 
yeterliklerinin belirlenmesi ve artırılması önemli hale gelmektedir (Koyuncu ve Haser, 2012).

\section{Çalışmanın Amacı}

Çalışmanın amacı doğrultusunda aşağıdaki problemlere yanıt aranmıştır:

1. Matematik öğretmeni adaylarının MOÖ ne düzeydedir?

2. Matematik öğretmeni adaylarının MOÖ düzeyleri ile baba ve anne eğitim durumları arasında anlamlı bir farklılık var mıdır?

3. Matematik öğretmeni adaylarının MOÖ düzeyleri cinsiyetlerine göre farklılaşmakta mıdır?

\section{Yöntem}

$\mathrm{Bu}$ bölümde, araştırma modeli, araştırma grubu, verilerin toplanması ile verilerin çözümlenmesi ile ilgili detaylı bilgilere yer verilmiştir.

\section{Araştırma Modeli}

Bu çalışma, ilişkisel tarama modeli kullanılarak gerçekleştirilmiştir. İlişkisel tarama modeli, "iki ya da daha fazla sayıdaki değişken arasında, birlikte değişim varlığı ve/veya derecesini belirleme" yi amaçlayan bir araştırma modelidir (Karasar, 1995, s. 76).

\section{Çalışma Grubu}

Bu çalışmaya, 2019-2020 eğitim-öğretim yılı güz döneminde Alanya Alaaddin Keykubat Üniversitesi Eğitim Fakültesi İlköğretim Matematik Öğretmenliği lisans programinda öğrenim gören $14^{\prime}$ ü erkek ve 59'u kadın olan toplam 73 son sinıf öğrencisi katılmıştır. Katılımcılar, kolayda örnekleme yöntemi ile tamamen gönüllülük esasına göre oluşturulmuştur. Bu yöntemle ankete cevap veren herkes örneğe dâhil edilerek (Altunışık, Coşkun, Bayraktaroğlu ve Yıldırım, 2005) az emek ve harcama ile büyük bir örnek hacme ulaşılabilir (Yazıcıoğlu ve Erdoğan, 2007).

\section{Veri Toplama Araçları ve Verilerin Toplanması}

$\mathrm{Bu}$ araştırma kapsamında Özgen ve Bindak (2008) tarafından geliştirilen Matematik Okuryazarlığı Öz-Yeterlik ölçeği ile Demografik Özellik anketi 2019-2020 eğitimöğretim yılı güz döneminde Alanya Alaaddin Keykubat Üniversitesi Eğitim Fakültesi İlköğretim Matematik Öğretmenliği bölümünde öğrenim gören son sınıf öğrencilerine uygulanmıştır.

Bu kapsamda, ilk olarak öğretmen adaylarının cinsiyet, anne ve baba eğitim durumlarına yer veren Demografik Özellik anketi adaylara uygulanmıştır. Ardından da, toplam 25 maddeden oluşan ve "Tamamen katılıyorum"dan "Hiç katılmıyorum"a doğru derecelendirilmiş 5'li likert türünde hazırlanmış olan Matematik Okuryazarlığ1 Öz-Yeterlik ölçeği adaylara yöneltilmiştir. Bu ölçekten alınabilecek en yüksek puan 125 ve en düşük puan ise $25^{\prime}$ tir.

\section{Verilerin Analizi}

$\mathrm{Bu}$ aşamada, ölçeği oluşturan ifadelerin tutarlılığını ve kullanılan ölçeğin katılımcılara yöneltilen soruları ne ölçüde yansıttığını belirlemek için (Kayış, 2008) güvenirlik analizi yapılmıştır. Güvenirlik, ifadelerin içsel tutarlığını ifade eden bir kavramdır (Hair vd., 2003). Bu araştırma kapsamında içsel tutarlılığın belirlenmesi 
için Cronbach alpha güvenirlik testi uygulanmış (Lewis vd. 2005, Altunışık vd. 2005) ve anketin Cronbach alpha değeri 0,89 olarak hesaplanmıştır.

İlköğretim Matematik Öğretmeni adaylarının Matematik Okuryazarlığ ÖzYeterlik ölçeğine verdikleri yanıtlarda olumsuz olarak tasarlanmış olan 6, 9, 18 ve 22. maddelere ilişkin yanıtlar tersten puanlandırılmıştır. Ardından her bir öğretmen adayı için toplam ve ortalama puanlar hesaplanmıştır. Grup içi puan aralıklarının genişliği belirlenerek ortalama puanlar yorumlanmıştır. Böylece “ölçme sonuçları dizisindeki en büyük değer ile en küçük değer arasındaki farkın belirlenen grup sayısına bölünmesiyle" (Kan, 2009: 407) grup aralık katsayısı değeri bulunmuştur. Buna göre katılımcıların yanıtlarının yorumlanabilmesi için değerlendirme aralığı (51) $/ 5=0,80$ olarak belirlenmiştir. Sonuç olarak da katılımcıların ölçeğe vermiş oldukları yanıtların yorumlanması için aralıklar 4,21-5,00 ile 1,00-1,80 puan arasında değişmiştir. $\mathrm{Bu}$ verilere ilişkin yüzde ve frekans değerlerine ulaşılmış ve gerçekleştirilen betimsel analizler üzerinden tablolaştırılarak bulgular kısmında sunulmuştur. Demografik Özellik anketinde yer alan bilgiler de sayısallaştırılarak bilgisayar sistemine aktarılmıştır. Araştırma verilerinin analizinde kullanılacak istatistiklerin belirlenmesi amacıyla çarpıklık (Skewness) ve basıklık (Kurtosis) değerleri gözden geçirilerek normal dağılım gösterip göstermediği incelenmiştir. Çarpıklık (Skewness) 0,476 ve basıklık (Kurtosis) 0,090 çıkmıştır. Kritik değerin çarpıklık için $-1,96$ ile $+1,96$ ve basıklık için -3 ile +3 aralığında olması gerekliliği (Hair vd. 2003) dikkate alındığında puanların normal dağılıma uygun olduğu sonucuna ulaşılmıştır. Ayrıca okuryazarlık ölçeğindeki puanların varyansının homojenliği Levene testi ile incelenmiş ve puanların homojen olduğu ( $L=0,093$; $\mathrm{p}=0,195)$ görülmüştür. Bu nedenle araştırmada parametrik istatistikler kullanılmıştır. Sonrasında araştırmaya katılan adayların demografik özellikler bakımından MOÖ verdikleri yanıtlar arasında anlamlı farklılığa sahip olup olmadıklarının tespiti için "Bağımsız İki Örnek T-Testi" (Independent-Samples t-Test) ve "Tek Yönlü Varyans Analizi" (One-Way ANOVA) uygulanmış ve farkın hangi gruptan kaynaklandığını anlamak için "Scheffe testi" yapılmıştır.

\section{Bulgular}

Bu bölümde ilk olarak, ilköğretim matematik öğretmeni adaylarının MOÖ’́nün incelenmesi amacıyla gerçekleştirilen analizler sonucunda elde edilen bulgulara yer verilmiştir. $\mathrm{Bu}$ kapsamda araştırmada "Hizmet öncesi matematik öğretmeni adaylarının MOÖ’leri ne düzeydedir?" şeklindeki birinci araştırma sorusuna yanıt aranırken, elde edilen araştırma verileri aşağıdaki tabloda sunulmuştur.

Tablo 1

Okuryazarlı Öz-yeterlik Ölçeği'nden Alınan Puanlara ilişkin Analiz Sonuçları

\begin{tabular}{|c|c|c|c|c|c|c|c|c|c|}
\hline \multicolumn{10}{|c|}{ Matematik okuryazarlık Öz-Yeterlik Ölçeği Puan Aralıkları } \\
\hline & aras1 & & aras1 & $\begin{array}{l}2,61 \\
\text { pua }\end{array}$ & aras1 & $\begin{array}{l}3,41 \\
\text { pua }\end{array}$ & arası & $\begin{array}{l}4,2 \\
\mathrm{pu}\end{array}$ & arasi \\
\hline $\mathrm{f}$ & $\%$ & $\mathrm{f}$ & $\%$ & $\mathrm{f}$ & $\%$ & $\mathrm{f}$ & $\%$ & $\mathrm{f}$ & $\%$ \\
\hline 0 & 0,0 & 0 & 0,0 & 13 & 17,81 & 51 & 69,86 & 9 & 12,33 \\
\hline
\end{tabular}


Yukarıdaki tablodan da anlaşılacağı üzere, bu araştırmaya katılan öğretmen adaylarının \%69,86'sının katılıyorum seçeneğini işaretleyerek 3,41-4,20 arasında puanlar alırken, \%17,81'inin kararsızım seçeneğini işaretleyerek 2,61-3,40 arasında puanlar aldıkları görülmektedir. Ayrıca, öğretmen adaylarının \%12,33'ü ise kesinlikle katılıyorum seçeneğini işaretleyerek 4,21-5,00 arası puan almışlardır. Öğretmen adaylarının yaklaşık olarak beşte dördünün 3,41-5,00 arasında puan almış olmaları, önemli bir bölümünün matematik okuryazarlık öz-yeterliklerinin gelişmiş olduğuna işaret etmektedir.

Araştırmanın ikinci sorusu "Matematik öğretmeni adaylarının MOÖ düzeyleri ile baba ve anne eğitim durumları arasında anlamlı bir farklılık var mıdır?" biçimindedir. Bu araştırma sorusuna yanıt aranırken, araştırma kapsamında elde edilen verilere uygulanan betimsel ve “Tek Yönlü Varyans Analizi” (One-Way ANOVA) sonuçları Tablo 2, Tablo 3 Tablo 4 ve Tablo 5 'te sunulmuştur. Bu kapsamda ilk olarak, araştırmaya katılan öğretmen adaylarının baba eğitim durumunu gösteren tablo aşağıda verilmiştir.

Tablo 2

Baba Ĕ̆itim Durumuna ilişkin Analiz Sonuçları

\begin{tabular}{cccccccccc}
\hline \multicolumn{2}{c}{ Diğer } & İlkokul & \multicolumn{2}{c}{ Ortaokul } & \multicolumn{2}{c}{ Lise } & \multicolumn{2}{c}{ Lisans } \\
\hline $\mathrm{f}$ & $\%$ & $\mathrm{f}$ & $\%$ & $\mathrm{f}$ & $\%$ & $\mathrm{f}$ & $\%$ & $\mathrm{f}$ & $\%$ \\
0 & 0,0 & 22 & 30,1 & 13 & 17,8 & 19 & 26,0 & 19 & 26,0 \\
\hline
\end{tabular}

Yapılan analizlerde, babası ortaokul mezunu olan aday sayısının diğerlerinden daha az olduğu görülürken diğer kategorilerde yaklaşık sayıda kişi bulunduğu anlaşılmıştır.

Tablo 3

Matematik Okuryazarlık Öz-yeterliğinin Baba Eğitim Durumuna Göre Karşılaştırılması

\begin{tabular}{lllllll}
\hline & Gruplar & Say1 & $\bar{x}$ & S.S. & F & p \\
\hline & Ilkokul & 22 & 3,75 & 0,36 & & \\
Baba Eğitim & Ortaokul & 13 & 3,86 & 0,37 & 0,708 & 0,551 \\
Durumu & Lise & 19 & 3,71 & 0,42 & & \\
& Lisans & 19 & 3,86 & 0,35 & & \\
\hline
\end{tabular}

Tablo 4

Anne Eğitim Durumuna ilişkin Analiz Sonuçları

\begin{tabular}{cccccccccc}
\hline \multicolumn{2}{c}{ Diğer } & \multicolumn{2}{c}{ İlkokul } & \multicolumn{2}{c}{ Ortaokul } & \multicolumn{2}{c}{ Lise } & \multicolumn{2}{c}{ Lisans } \\
\hline $\mathrm{f}$ & $\%$ & $\mathrm{f}$ & $\%$ & $\mathrm{f}$ & $\%$ & $\mathrm{f}$ & $\%$ & $\mathrm{f}$ & $\%$ \\
1 & 1.4 & 28 & 38.4 & 14 & 19.2 & 25 & 34.2 & 5 & 6.8 \\
\hline
\end{tabular}

Yapılan analizlerde, adayların annelerinin çoğunlukla $(\% 72,6)$ ilkokul ve lise mezunu oldukları görülmüştür. 
Tablo 5

Matematik Okuryazarlık Öz-yeterliğinin Anne Eğitim Durumuna Göre Karşılaştırılması

\begin{tabular}{lllllll}
\hline & Gruplar & Say1 & $\overline{\mathrm{x}}$ & S.S. & F & $\mathrm{p}$ \\
\hline \multirow{3}{*}{ Anne Eğitim } & İlkokul & 28 & 3,72 & 0,37 & & \\
Durumu & Ortaokul & 14 & 3,76 & 0,45 & 0,854 & 0,496 \\
& Lise & 25 & 3,85 & 0,31 & & \\
& Lisans & 5 & 3,91 & 0,48 & & \\
\hline
\end{tabular}

Yukarıdaki bilgilerden anlaşılacağı üzere, araştırmaya katılan öğretmen adaylarının okuryazarlık öz-yeterlik puanları ile baba ve anne eğitim durumları arasında anlamlı bir farkın olmadığı görülmektedir. Öğretmen adaylarının baba ve anne eğitim durumları değişse de MOÖ yönündeki yanıtları arasında anlamlı bir fark bulunmamaktadır. Bu durum, baba ve annenin eğitim durumunun MOÖ'yü etkilemediği sonucunu göstermektedir.

Araştırmanın üçüncü sorusu, "Matematik öğretmeni adaylarının MOÖ düzeyleri cinsiyetlerine göre farklılaşmakta mıdır?" biçimindedir. Bu araştırma sorusuna yanıt aranırken, araştırma kapsamında elde edilen verilere uygulanan Bağımlı Örneklem t-Testi sonuçları Tablo 6' da sunulmuştur.

Tablo 6

Okuryazarlık ile Cinsiyet Arasındaki Değişim Durumunu Açıklayan Analiz Sonuçları

\begin{tabular}{llll}
\hline & $\mathrm{n}$ & $\mathrm{t}$ & $\mathrm{p}$ \\
\hline $\begin{array}{l}\text { Matematik Okuryazarlık Öz-Yeterlik Puanları } \\
\text { Cinsiyet }\end{array}$ & 73 & $25,91^{*}$ & 0,00 \\
\hline${ }^{*} \mathrm{p}<0,01$ & & & \\
\hline
\end{tabular}

Yapılan analizlerde, araştırmaya katılan öğretmen adaylarının okuryazarlık öz-yeterlik puanları ile cinsiyetleri arasında anlamlı bir farklılık olduğu anlaşılmaktadır $(t=25,91 ; p=0,00)$. Erkek öğretmen adaylarının öz-yeterlik puan ortalamasının $(2,16)$ kadın öğretmen adaylarının puan ortalamasından $(2,94)$ düşük olması da kadın öğretmen adaylarının MOÖ düzeylerinin daha yüksek olduğuna işaret etmektedir. Bu durum kadın öğretmen adaylarının MOÖ’lerinin daha gelişmiş olduğunu göstermektedir.

\section{Tartışma, Sonuç ve Öneriler}

$\mathrm{Bu}$ çalışmada Alanya Alaaddin Keykubat Üniversitesinde öğrenim görmekte olan ilköğretim matematik öğretmeni adaylarının MOÖ düzeylerinin; cinsiyet ve annebaba eğitim durumlarına göre farklılık gösterip göstermediği araştırılmıştır.

$\mathrm{Bu}$ araştırmada ilköğretim matematik öğretmeni adaylarının MOÖ düzeylerinin ortalamanın üzerinde olduğu görülmektedir. Bu durum, araştırmaya katılan öğretmen adaylarının büyük bölümünün MOÖ’lerinin gelişmiş olduğunu göstermektedir. Benzer şekilde Yenilmez ve Turğut (2012), Güneş ve Gökçek (2013), Tarım vd. (2015), Dinçer vd. (2016) de yaptıkları çalışmalarda araştırmaya katılan öğretmen adaylarının MOÖ düzeylerinin yüksek olduğunu belirtmektedirler. Elde 
edilen sonuçlar, öğretmen adaylarının okuduğunu anladığını ve anlatabildiğini açıllamaktadır.

Matematik öğretmen adaylarının MOÖ düzeyleri ile anne-baba eğitim durumu incelendiğinde aralarında anlamlı bir ilişki bulunmamıştır. Anne-baba eğitim durumunun matematik okuryazarlık öz-yeterlik düzeyine herhangi bir katkısının olmadığı saptanmıştır. Elde edilen bu sonuç, Koyuncu ve Haser (2012) ve Zehir ve Zehir'in (2016) yaptıkları çalışmaları destekler niteliktedir. Buna karşın, Cooper ve Robinson (1991) yaptıkları çalışmada matematik öz yeterliliği ile annebaba eğitimi arasında düşük düzeyde bir ilişki olduğunu ve anne-baba desteğinin önemli olduğunu vurgulamışlardır (aktaran Zehir ve Zehir, 2016).

$\mathrm{Bu}$ araştırmada matematik öğretmen adaylarının MOÖ düzeyleri ile cinsiyetleri arasında anlamlı bir ilişki bulunmuştur. Bu durum, kadın öğretmen adaylarının MOÖ düzeylerinin erkek öğretmen adaylarının MOÖ düzeylerinden daha yüksek olduğunu göstermektedir. Benzer sonuçlar, Zehir ve Zehir (2016) tarafından da bulunmuştur. Ayrıca, Gömleksiz ve Öner (2011), kadın öğretmen adaylarının bilginin değerlendirilmesi ve kullanılması konusunda erkek öğretmen adaylarına göre daha başarılı olduklarını ifade etmektedirler. Columbia Üniversitesi'nde yapılan bir çalışmaya göre kadınların, sebat, öğrenme isteği, bir konuyu kendi kendine çalışarak öğrenme ölçütlerinde daha başarılı oldukları (Sekman ve Eriş, 2017) göz önüne alındığında bu kavramların özyeterlik kavramı ile paralellik göstermesi çalışmanın sonuçlarını destekler niteliktedir. Çalışmanın sonucu; Yenilmez ve Turğut (2012), Tarım vd. (2015), Dinçer vd.'nin (2016) yaptıkları çalışmadan farklılık göstermektedir.

Çağdaş eğitimin en önemli ilkesi, eğitimin sürekli olmasıdır. Bilgi çağında eğitimden beklenilen nitelik değişmekte ve değişirken de gelişmesi beklenmektedir. Matematik öğretmen adaylarının MOÖ düzeylerinin geliştirilmesi için eğitim fakültelerinde verilen eğitimin nitelikli hale gelmesi gerekmektedir. Okullarda matematik ders programı okuryazarlığı, mantıksal akıl yürütme, matematik öğretiminde kavram yanılgıları gibi derslere ağırlık verilmesi öğretmen adaylarının okuryazarlık öz-yeterlikleri açısından önem kazanacaktır.

Matematik öğretmen adaylarının MOÖ'lerinin gelişmesi; düşünme, sorgulama ve üretme yeteneklerin gelişmesine katkı sağlayacaktır. Ülkemizde verilen matematik eğitiminin uluslararası standartlara gelebilmesi iyi yetişen öğretmenler sayesinde olacaktır. Öğretmen adaylarının okuryazarlık öz-yeterlik düzeylerinin artması yetiştirecekleri öğrencilerin ve verecekleri eğitimin gelişmesini sağlayacaktır.

Bundan sonra yapılacak çalışmalarda, cinsiyet ve anne-baba eğitim düzeyi dışında sosyo-ekonomik durum ve sınıf düzeyinde de matematik okuryazarlı̆̆ı özyeterliği düzeylerinin ölçülmesi önerilmektedir.

\section{Kaynakça}

Akgün, F. (2013). Öğretmen Adaylarının Web Pedagojik İçerik Bilgileri ve Öğretmen Öz-Yeterlik Algıları İle İlişkisi. Trakya Üniversitesi Eğitim Fakültesi Dergisi, 3(1), 48-58.

Akkoyunlu, B. (1995). Bilgi Teknolojilerinin Okullarda Kullanımı ve Öğretmenlerin Rolü. Hacettepe Üniversitesi Eğitim Fakültesi Dergisi, 11(11), 105-109. 
Akkoyunlu, B. ve Kurbanoğlu, S. (2003). Öğretmen Adaylarının Bilgi Okuryazarlı̆̆1 ve Bilgisayar Öz-Yeterlik Algıları Üzerine Bir Çalışma. Hacettepe Üniversitesi Ĕ̌itim Fakültesi Dergisi, 24(24), 1-10.

Akkoyunlu, B. ve Kurbanoğlu, S. (2004). Öğretmenlerin Bilgi Okuryazarlı̆̆g ÖzYeterlik İnancı Üzerine Bir Çalışma. Hacettepe Üniversitesi Eğitim Fakültesi Dergisi, 27(27), 11-20.

Aksu, G. ve Güzeller, C. O. (2016). PISA 2012 Matematik Okuryazarlığ1 Puanlarının Karar Ağacı Yöntemiyle Sınıflandırılması: Türkiye Örneklemi. Eğitim ve Bilim, 41(185), 101-122.

Altıntaş, E., Özdemir, A. Ş. ve Kerpiç, A. (2012). Öğretmen Adaylarının Matematik Okuryazarlığı Özyeterlik Algılarının Bölümlere Göre Karşılaştırılması. Trakya Üniversitesi Eğitim Fakültesi Dergisi, 2(2), 26-34.

Altunışık, R., Coşkun, R., Bayraktaroğlu, S. ve Yıldırım, E. (2005). Sosyal Bilimlerde Araştırma Yöntemleri SPSS Uygulamalı. (4.Bask1). Sakarya Kitabevi: Sakarya.

Aşkar, P. ve Umay, A. (2001). İlköğretim Matematik Öğretmenliği Öğrencilerinin Bilgisayarla İlgili Öz-Yeterlik Algısı. Hacettepe Üniversitesi Eğitim Fakültesi Dergisi, 21(21), 1-8.

Aydın, B. (2003). Bilgi Toplumu Oluşumunda Bireylerin Yetiştirilmesi ve Matematik Öğretimi. Pamukkale Üniversitesi Eğitim Fakültesi Dergisi, 14(2), 183-190.

Bandura, A. (2010). Self-Efficacy. In I. B. Weiner and W. E. Craighead (Ed.), Corsini Encyclopedia of Psychology (Vol. 4), New York, Wiley. https:// doi.org/10.1002/9780470479216.corpsy0836

Başaran, M. (2015). Sınıf Öğretmeni Adaylarının Bilgi Okuryazarlıklarının Değerlendirilmesi. Gazi Eğitim Fakültesi Dergisi, 25(3), 163-177.

Büyüköztürk, Ş. (2010). Sosyal bilimler için veri analizi el kitabı. Ankara: Pegem Yayıncilik, s. 170.

Çapa, Y., Çakıroğlu, J. ve Sarıkaya, H. (2005). Öğretmen Özyeterlik Ölçeği Türkçe Uyarlamasının Geçerlik ve Güvenirlik Çalışması. Eğitim ve Bilim, 30(137), 7487.

Çilingir, E. ve Artut, P. D. (2016). Gerçekçi Matematik Eğitimi Yaklaşımının İlkokul Öğrencilerinin Başarılarına, Görsel Matematik Okuryazarlı̆̆ı Özyeterlik Algilarına ve Problem Çözme Tutumlarına Etkisi. Turkish Journal of Computer and Mathematics Education, 7(3), 578-600.

Demirtaş, H., Cömert, M. ve Özer, N. (2011). Öğretmen Adaylarının Özyeterlik İnançları ve Öğretmenlik Mesleğine İlişkin Tutumları. Eğitim ve Bilim, 36(159), 96-111.

Dinçer, B., Akarsu, E. ve Yılmaz, S. (2016). İlköğretim Matematik Öğretmeni Adaylarının Matematik Okuryazarlığı Özyeterlik Algıları İle Matematik Öğretimi Yeterlik İnanç Düzeylerinin İncelenmesi. Turkish Journal of Computer and Mathematics Education (TURCOMAT), 7(1), 207-228.

Duran, M. ve Bekdemir, M. (2013). Görsel Matematik Okuryazarlığ Özyeterlik Algısıyla Görsel Matematik Başarısının Değerlendirilmesi. Pegem Eğitim ve Öğretim Dergisi, 3(3), 27-40.

Ersoy, Y. (1997). Okullarda Matematik Eğitimi: Matematikte Okur Yazarlık. Hacettepe Üniversitesi Eğitim Fakültesi Dergisi, 13(13), 115-120. 
Gömleksiz, M. N. ve Öner, Ü. (2011). Öğretmen adaylarının bilgi okuryazarlığı becerilerindeki zorlanma düzeyleri, e-Journal of New World Sciences Academy, 6(1), 119-138.

Güneş, G. ve Gökçek, T. (2013). Öğretmen Adaylarının Matematik Okuryazarlık Düzeylerinin Belirlenmesi. Dicle Üniversitesi Ziya Gökalp Eğitim Fakültesi Dergisi, 20, 70-79.

Hair, J. F., Babin, B., Money, A.H., and Samouel, P. (2003). Essentials of Business Research Methods. United States of America: John Wiley and Sons.

İlhan, A. (2015). İlköğretim Matematik Öğretmen Adaylarına Yönelik Görsel Matematik Okuryazarlı̆̆ı Ölçeğinin Geliştirilmesi ve Görsel Matematik Okuryazarlı̆̆ı İle Geometri Başarıları Arasındaki İlişkisinin İncelenmesi. (Yüksek lisans tezi). Furat Üniversitesi, Eğitim Bilimleri Enstitüsü, Elazı̆̆.

Kan, A. (2009). Ölçme Sonuçları Üzerinde İstatistiksel İşlemler. H. Atılgan (Ed.), Ĕ̆itimde Ölçme ve Değgerlendirme (ss.397-456). Ankara: Anı Yayınc1lı. Karasar, N. (2003). Bilimsel Araştırma Yöntemi (12.Bask1). Ankara: Nobel Yayıncılık. Kayış, A. (2008). Güvenilirlik Analizi (Reliability Analysis). Ş. Kalaycı (Ed.). SPSS Uygulamalı Çok Değiş̧kenli İstatistik Teknikleri. Ankara: Asil Yayın Dağıtım.

Koyuncu, İ. ve Haser, Ç. (2012). Sınıf Öğretmeni Adaylarının Matematik Okuryazarlı̆̆ı Öz-Yeterlik Düzeyleri İle Akademik Başarıları Arasındaki İlişkinin İncelenmesi. 10. Ulusal Fen Bilimleri ve Matematik Ĕgitimi Kongresi, Niğde Üniversitesi, Niğde.

Lewis, B. R., Templeton, G. F., and Byrd, T. A. (2005). A Methodology for Construct Development in MIS Research. European Journal of Information Systems, 14 (4), 388-400. https:/ / doi.org/10.1057/palgrave.ejis.3000552

MEB Matematik Dersi Öğretim Programı, 2018. Adres:

http:/ / mufredat.meb.gov.tr/Dosyalar/201813017165445MATEMAT\%C4\%B0 K\%20\%C3\%96\%C4\%9ERET\%C4\%B0M\%20PROGRAMI\% 202018v.pdf (Erişim tarihi 08.10.2019)

Özgen, K. ve Bindak, R. (2008). Matematik Okuryazarlı̆̆ ${ }_{1}$ Öz-Yeterlik Ölçeğinin Geliştirilmesi. Kastamonu Eğitim Dergisi, 16(2), 517-528.

PISA 2012 Ulusal Nihai Raporu. Adres: http:// pisa.meb.gov.tr/?page_id=22 (Erişim Tarihi: 07.10.2019)

PISA 2015 Ulusal Raporu. Adres: http:/ / pisa.meb.gov.tr/wpcontent/uploads/2014/11/PISA2015_UlusalRapor.pdf (Erişim Tarihi: 07.10.2019)

Önal, N. ve Çetin, O. (2014). Öğretmen Adaylarının Bilgi Okuryazarlıklarının Çeşitli Değişkenler Açısından İncelenmesi. Mehmet Akif Ersoy Üniversitesi Ĕ̆itim Fakültesi Dergisi, 29, 1-30.

Özsoy-Güneş, Z., Çıngıl-Barış, Ç. ve Kırbaşlar, F. (2013). Fen Bilgisi Öğretmen Adaylarının Matematik Okuryazarlığ ${ }_{1}$ Öz-Yeterlik Düzeyleri İle Eleştirel Düşünme Eğilimleri Arasındaki İlişkilerin İncelenmesi. HAYEF Journal of Education, 10(1), 47-64.

Sekman, M. ve Eriş, B. (2017). Çocuklar Nasıl Başarır? Alfa Eğitim, İstanbul. Senemoğlu, N. (2001). Gelişim, Öğrenme ve Öğretim. Gazi Kitabevi, Ankara. Tarım, K. ve Baypınar, K. ve Keklik, G. (2015). İlköğretim Öğretmenlerinin Matematik Okuryazarlığı Öz-Yeterlik Düzeylerinin Çeşitli Değişkenler 
Açısından İncelenmesi. Adıyaman Üniversitesi Sosyal Bilimler Enstitüsü Dergisi, 2015(21), 846-870.

Uysal, E. ve Yenilmez, K. (2011). Sekizinci Sınıf Öğrencilerinin Matematik

Okuryazarlığ1 Düzeyi. Eskişehir Osmangazi Üniversitesi Sosyal Bilimler

Dergisi, 12(2), 1-15.

Yazıcıoğlu, Y. ve Erdoğan, S. (2014). SPSS Uygulamah Bilimsel Araştırma Yöntemleri. Detay Yayıncilık.

Yenilmez, K. ve Turğut, M. (2012). Matematik Öğretmeni Adaylarının Matematik

Okuryazarlı̆̆ı Özyeterlik Düzeyleri. Ĕ̆itim ve Öğretim Araştırmaları

Dergisi, 1(2), 253-258.

Zehir, K. ve Zehir, H. (2016). İlköğretim Matematik Öğretmen Adaylarının

Matematik Okuryazarlığı Öz-Yeterlik İnanç Düzeylerinin Çeşitli Değişkenler

Açısından İncelenmesi. Uluslararası Eğitim Bilim ve Teknoloji Dergisi, 2(2), 104117.

\section{Summary}

\section{Introduction}

When the definitions related to literacy are examined in the literature, it is seen that another concept associated with literacy is self-efficacy, apart from the interest in mathematics, attitude, motivation, perception, anxiety and discipline of study (Aksu and Güzeller, 2016). However, in PISA 2012, where mathematical literacy is determined as a predominant field, Turkey ranked 31st among the 34 OECD countries. The fact that Turkish students are in the last place in PISA exams shows that their perceptions of mathematical self-efficacy are not sufficient. According to these results, students are insufficient to think critically and analytically, to produce results and to pass these results into their daily lives. While investigating the cause of insufficiency, the question of whether the low self-efficacy levels of teachers has an effect comes to mind. Strengthening the self-efficacy perceptions of these students depends only on teachers by conducting teaching activities in accordance with the needs and qualifications of their students (Senemoğlu, 2001).

Since the preschool period mathematics exists in all areas of our lives and many knowledge and skills are gained by primary teachers in primary education, primary school teachers are expected to have a high MLS (Mathematics Literacy SelfEfficacy). For a qualified and successful mathematics teaching, some precautions should be taken before the service (Yenilmez and Turğut, 2012) in terms of the development of MLS of teacher candidates (Koyuncu and Haser, 2012) and their professional development. In order to have high MLS for mathematical teacher candidates, the development of thinking, questioning and producing skills should be in the first place when these measures are taken. For this reason, it is aimed to determine the levels of MLS of primary mathematics teacher candidates. Accordingly, the aim of this study is to determine whether the answers of primary mathematics teacher candidates to questions about MLS levels differ according to their parents' education status and gender. 


\section{Method}

This study was carried out using the relational scanning model. 73 senior students (14 males and 59 females) studying at the Faculty of Education, Primary Mathematics Education undergraduate program participated in the study.

Within the scope of this research, the Demographic Feature survey was conducted with the Mathematical Literacy Self-Efficacy scale developed by Özgen and Bindak (2008). Cronbach's alpha reliability test was applied to determine the internal consistency within the scope of the study and the Cronbach's alpha value of the questionnaire was calculated as .89 .

In order to determine the statistics to be used in the analysis of the research data, the skewness and kurtosis values were examined and the skewness was found as .476 and the kurtosis as .090. Hair et al. (2003), it was concluded that the scores were suitable for a normal distribution. In addition, the homogeneity of the variant of the literacy scale was examined by the Levene test and it was observed that the scores were homogeneous $(\mathrm{L}=0.093 ; \mathrm{p}=0.195)$. "Independent-Samples $t$-Test" and "One-Way Variance Analysis" (One-Way ANOVA) were administered to determine whether the candidates who participated in the study differed significantly regarding their responses to the MLS in terms of demographic characteristics, and a "Scheffe test" was conducted to determine which group the difference originated from.

\section{Results}

Firstly, in the study, an answer was sought to the first research question of "What is the MLS level of pre-service mathematics teacher candidates?" While $69.86 \%$ of the teacher candidates participating in the study got scores between 3.41 and 4.20, $17.81 \%$ got scores between 2.61 and 3.40 . In addition, $12.33 \%$ of the teacher candidates got scores between 4.21-5.00. This situation indicates that a significant portion of the pre-service teachers have developed mathematical literacy selfefficacy.

The second question of the study is "Is there a significant difference between the MLS levels of mathematics teacher candidates and the status of their parens' education?" In the analysis, it was observed that the number of candidates whose fathers were secondary school graduates was less than the others and that the mothers of the candidates were mostly primary and high school graduates $(72.6 \%)$. It is seen that there is no significant difference between literacy self-efficacy scores and father and mother education status. This indicates that the educational status of the parents does not affect the MLS.

The third question of the study is "Does MLS levels of math teacher candidates differ according to their gender?" It is understood that there is a significant difference between literacy self-efficacy scores and their gender $(t=25.91$; $p=0.00)$. This situation shows that the MLSs of female teacher candidates $(\bar{x}=2,94)$ are more developed than male teacher candidates $(\bar{x}=2.16)$.

\section{Discussion and Conclusion}

In this study, it is seen that primary school mathematics teacher candidates have above average levels of MLS and thus their MLSs have improved. Similarly, Yenilmez and Turğut (2012), Güneş and Gökçek (2013), Tarım et al. (2015), Dinçer et 
al. (2016) stated in their studies that the pre-service teachers who participated in the study had high levels of MLS. The results explain that teacher candidates understand and explain what they read.

It has been determined that the status of parents education does not contribute to the level of mathematics literacy self-efficacy to the MLS levels of mathematics teacher candidates. This result supports the sudy of Koyuncu and Haser (2012) and Zehir and Zehir (2016). On the other hand, Cooper and Robinson (1991) emphasized in their study that there is a low-level relationship between mathematics self-efficacy and parents' education and that parents' support is important (as cited in Zehir and Zehir, 2016).

In this study, when the levels of MLS and gender of mathematics teacher candidates are examined, it is seen that the MLS levels of female teacher candidates are higher than the MLS levels of male teacher candidates. Similar results were found by Zehir and Zehir (2016). In addition, Gömleksiz and Öner (2011) state that female teacher candidates are more successful than male teacher candidates in evaluating and using knowledge.

In order to improve MLS levels of mathematics teacher candidates, the education given in the faculty of education must become qualified. Emphasis on courses such as mathematics curriculum literacy, logical reasoning and misconceptions in mathematics teaching will gain importance in terms of the literacy self-efficacy of teacher candidates.

\section{Pedagogical Implications}

The development of the MLS of mathematics teacher candidates will contribute to the development of thinking, questioning and producing abilities. Increasing the literacy self-efficacy levels of prospective teachers will enable the development of the students they will train and their education.

\section{Araştırmanın Etik Taahhüt Metni}

Yapılan bu çalışmada bilimsel, etik ve alıntı kurallarına uyulduğu; toplanan veriler üzerinde herhangi bir tahrifatın yapılmadığı, karşılaşılacak tüm etik ihlallerde "Cumhuriyet Uluslararası Eğitim Dergisi ve Editörünün" hiçbir sorumluluğunun olmadığı, tüm sorumluluğun Sorumlu Yazara ait olduğu ve bu çalışmanın herhangi başka bir akademik yayın ortamına değerlendirme için gönderilmemiş olduğu sorumlu yazar tarafından taahhüt edilmiştir.

\section{Authors' Biodata/ Yazar Bilgileri}

Bünyamin AYDIN Necmettin Erbakan Üniversitesi Ahmet Keleşoğlu Eğitim Fakültesi'nde Profesör Doktor olarak çalışmaktadır.

Bünyamin Aydın has been working as Professor Doctor in Necmettin Erbakan University Ahmet Keleşoğlu Faculty of Education.

Şefika ÇULHA Alanya Alaaddin Keykubat Üniversitesi Matematik ve Fen Bilimleri Eğitimi anabilim dalında tezli yüksek lisans öğrencisidir. 
Şefika Çulha is a master student at the Department of Mathematics and Science Education in Alanya Alaaddin Keykubat University.

Gizem YEŞİLGÖZ ŞENGÜN Toslak Sabir Erkin Ortaokulu'nda matematik öğretmeni olarak çalışmaktadır.

Gizem Yeşilgöz Şengün has been working as mathematics teacher at Toslak Sabir Erkin Secondary School. 